\title{
Monopolist's mark-up and the elasticity of substitution
}

\author{
Ilko Vrankić ${ }^{1}$, Mira Krpan ${ }^{1, \dagger}$ and Tomislav Herceg ${ }^{1}$ \\ ${ }^{1}$ Department of Economic Theory, Faculty of Economics and Business, University of \\ Zagreb, J. F. Kennedy 6, 10000 Zagreb, Croatia \\ E-mail: 〈\{ivrankic, mkrpan, therceg\}@efzg.hr 〉
}

\begin{abstract}
This paper analyzes the mark-up of the price of a product over marginal costs for a monopolist using Appelbaum's theoretical model. The profit maximization model of an industry that uses the monopolist's product as its input is formulated. Our goal is to express the monopolist's mark-up as a function of the elasticity of substitution for the respective industry and to analyze how changes in the elasticity of substitution affect the mark-up ratio. Consequently, the CES production function along with its substitution parameter is chosen. An analytical description of changes in the elasticity of substitution and its influence on the monopolist's mark-up is given. All scenarios are supplemented by geometrical illustrations, economic interpretations and numerical examples.
\end{abstract}

Keywords: profit maximization, monopolist, mark-up, elasticity of substitution

Received: September 30, 2016; accepted: June 19, 2017; available online: November 30, 2017

DOI: $10.17535 /$ crorr. 2017.0024

\section{Introduction}

Identifying and measuring market power in product markets has drawn the attention of numerous economists, due to the influence of market power on overall economic performance [4,9]. The most direct indicator of monopoly power is the mark-up ratio, which is defined as the ratio of difference between the price and a firm's marginal cost to price, known in literature as the Lerner index [7]. Since marginal costs are not directly observable, empirical measuring them empirically is relatively difficult. A new methodology in estimating the mark-up of prices over marginal costs at an aggregate level was devised in the late 1980-s [6] and uses the Solow residual. Due to some criticism of Hall's approach to its empirical application, Roeger modified Hall's original method [8].

Appelbaum [1] in his analysis, unlike other studies in which the degree of monopoly is measured, offers a framework for testing the price using a behavioral hypothesis for the industry and applying it to the U.S. crude petroleum and natural

$\dagger$ Corresponding author 
gas industry. This framework for analyzing a non-competitive industry or firm is the basis for our paper. The mark-up of product price over marginal costs as a direct indicator of imperfect competition is analyzed using a theoretical model to formulate the profit maximization model of an industry that uses the monopolist's product as its input. The industry's technology is described by the CES production function and is chosen given the existence of the substitution parameter, which in turn is used in calculating the elasticity of substitution and measures the ease of substitution between the monopolist's input and other inputs of the respective industry. The solution of the necessary first-order conditions for the industry's profit maximization model yields the demand function for the monopolist's product. The next step involves using a derived demand function and solving a monopolist's profit maximization model. The goal of this paper is to express the monopolist's mark-up as a function of the industry's elasticity of substitution and to analyze how changes in the elasticity of substitution affect the mark-up ratio.

In practice, this model is applicable to many industries. For instance, one such industry is the graphite lead industry, where graphite pencils initially used pure graphite for the lead which was very expensive, resulting in low volumes manufactured. This will be later explained relying on the lower boundary of the elasticity of substitution between inputs. Once pure graphite was replaced with cheaper unclean graphite and mixed with clay, both of which are abundantly available, demand for pure graphite fell and in time the graphite monopoly collapsed as did its producer. This again will be explained later using the upper boundary of the elasticity of substitution.

\section{The monopolist's mark-up}

Let's analyze first an industry and suppose that its technology is represented by a constant elasticity of substitution (CES) production function,

$$
G\left(y_{0}, \mathbf{x}\right)=\left[\delta y_{0}^{\rho}+(1-\delta) \mathbf{x}^{\rho}\right]^{\frac{v}{\rho}}, 0<\delta<1, v>0,0 \neq \rho<1
$$

where $y_{0}$ and $\mathbf{x}$ are quantities of inputs used in the production process by an industry, $\delta$ is the distribution parameter, $v$ is the scale parameter and $\rho$ is the substitution parameter. Let's assume that one of the inputs the industry uses is produced by a monopolist and the quantity is represented by $y_{0}$ and $\mathbf{x}$ is the vector of other inputs used in the production process of an industry. 
An industry maximizes profit by choosing optimal quantities of inputs subject to given prices of inputs and the profit maximization model of an industry is formulated as [1]:

$$
\max _{y_{0}, \mathbf{x}} w_{0} G\left(y_{0}, \mathbf{x}\right)-p_{0} y_{0}-\mathbf{w} \mathbf{x}
$$

where $w_{0}$ is the price of an industry product, $p_{0}$ is the monopolist's product price and $\mathbf{w}$ is the vector of other input prices. By differentiating the goal function with respect to the decision variables, the first-order necessary conditions are obtained,

$$
\begin{gathered}
p_{0}=w_{0} \frac{\partial G\left(y_{0}, \mathbf{x}\right)}{\partial y_{0}} \\
\mathbf{w}=w_{0} \nabla_{\mathbf{x}} G\left(y_{0}, \mathbf{x}\right),
\end{gathered}
$$

and the solution to the system of equations gives the demand functions for inputs, $y_{0}\left(p_{0}\right), \mathbf{x}\left(p_{0}\right)$. We suppose that the second-order sufficient conditions are satisfied.

Given that we have chosen the CES production function, the profit maximization model of an industry is defined as

$$
\max _{y_{0}, \mathbf{x}} w_{0}\left[\delta y_{0}^{\rho}+(1-\delta) x^{\rho}\right]^{\frac{v}{\rho}}-p_{0} y_{0}-w x
$$

where we assume, without the loss of generality, that the industry, in addition to the monopolist's product as input employs one more input where the quantity is represented by $x$, and price is represented by $w$. By differentiating the goal function in (4) with respect to the quantities of inputs, the following system of equations is obtained. The solutions are the demand functions for the monopolist's product and for the other input,

$$
\begin{gathered}
p_{0}=w_{0} \frac{\partial G\left(y_{0}, x\right)}{\partial y_{0}}=w_{0} \delta v\left[\delta y_{0}{ }^{\rho}+(1-\delta) x^{\rho}\right]^{\frac{\nu}{\rho}-1} y_{0}^{\rho-1} \\
w=w_{0} \frac{\partial G\left(y_{0}, x\right)}{\partial x}=w_{0}(1-\delta) v\left[\delta y_{0}{ }^{\rho}+(1-\delta) x^{\rho}\right]^{\frac{\nu}{\rho}-1} x^{\rho-1}
\end{gathered}
$$


Due to functional form of the chosen CES production function, the computation is somewhat tedious, hence it will be presented further on in the paper.

Let's express the quantity of input, $x$, as a function of the monopolist's product quantity,

$$
\begin{aligned}
& {\left[\delta y_{0}{ }^{\rho}+(1-\delta) x^{\rho}\right]^{\frac{v}{\rho}-1} y_{0}{ }^{\rho-1}=\frac{p_{0}}{w_{0} \delta v} \quad \quad \quad \frac{x^{\rho-1}}{y_{0}{ }^{\rho-1}}=\frac{w \delta}{p_{0}(1-\delta)}} \\
& \left.\left[\delta y_{0}{ }^{\rho}+(1-\delta) x^{\rho}\right]^{\frac{\nu}{\rho}-1} x^{\rho-1}=\frac{w}{w_{0}(1-\delta) v}\right\} x=\left[\frac{w \delta}{p_{0}(1-\delta)}\right]^{\frac{1}{\rho-1}} y_{0}
\end{aligned}
$$

Our interest in this paper is to obtain the demand function for the monopolist's product and incorporate it into the monopolist's profit maximization model in order to express the mark-up of monopolist's product price over marginal cost as a function of the elasticity of substitution.

The next step in deriving the demand function for the monopolist's product involves inserting (6) into the first equation of (5), and hence obtain the demand function for the monopolist's product,

$$
\begin{aligned}
& \left\{\delta y_{0}{ }^{\rho}+(1-\delta)\left[\frac{w \delta}{p_{0}(1-\delta)}\right]^{\frac{\rho}{\rho-1}} y_{0}^{\rho}\right\}^{\frac{v-\rho}{\rho}} y_{0}^{\rho-1}=\frac{p_{0}}{w_{0} \delta v} \\
& {\left[\delta+(1-\delta)^{-\frac{1}{\rho-1}}\left(\frac{w \delta}{p_{0}}\right)^{\frac{\rho}{\rho-1}}\right]^{\frac{v-\rho}{\rho}} y_{0}{ }^{v-1}=\frac{p_{0}}{w_{0} \delta v}} \\
& {\left[\delta^{-\frac{1}{\rho-1}}+(1-\delta)^{-\frac{1}{\rho-1}}\left(\frac{w}{p_{0}}\right)^{\frac{\rho}{\rho-1}}\right]^{\frac{v-\rho}{\rho}} \delta^{\frac{v-\rho}{\rho-1}} y_{0}{ }^{v-1}=\frac{p_{0}}{w_{0} \delta v}}
\end{aligned}
$$




$$
\begin{aligned}
& {\left[\delta^{-\frac{1}{\rho-1}} p_{0}^{\frac{\rho}{\rho-1}}+(1-\delta)^{-\frac{1}{\rho-1}} w^{\frac{\rho}{\rho-1}}\right]^{\frac{v-\rho}{\rho}} y_{0}{ }^{\nu-1}=\frac{1}{w_{0} v} p_{0}^{\frac{v-1}{\rho-1}} \delta^{\frac{1-v}{\rho-1}}} \\
& {\left[\left(\frac{p_{0}{ }^{\rho}}{\delta}\right)^{\frac{1}{\rho-1}}+\left(\frac{w^{\rho}}{1-\delta}\right)^{\frac{1}{\rho-1}}\right]^{\frac{v-\rho}{\rho}} y_{0}{ }^{v-1}=\frac{1}{w_{0} v}\left(\frac{p_{0}}{\delta}\right)^{\frac{1-v}{\rho-1}}} \\
& y_{0}{ }^{{ }^{-1}}=\frac{1}{w_{0} v}\left(\frac{p_{0}{ }^{\rho}}{\delta}\right)^{\frac{v-1}{\rho-1}}\left[\left(\frac{p_{0}{ }^{\rho}}{\delta}\right)^{\frac{1}{\rho-1}}+\left(\frac{w^{\rho}}{1-\delta}\right)^{\frac{1}{\rho-1}}\right]^{\frac{\rho-v}{\rho}} \\
& y_{0}=\left(w_{0} v\right)^{\frac{1}{1-v}}\left(\frac{p_{0}}{\delta}\right)^{\frac{1}{\rho-1}}\left[\left(\frac{p_{0}{ }^{\rho}}{\delta}\right)^{\frac{1}{\rho-1}}+\left(\frac{w^{\rho}}{1-\delta}\right)^{\frac{1}{\rho-1}}\right]^{\frac{\rho-v}{\rho(v-1)}}
\end{aligned}
$$

Let's now focus on the monopolist's profit maximization model. We chose to take the monopolist's product price as his decision variable instead of the output quantity, hence the monopolist's profit maximization problem is formulated as follows:

$$
\max _{p_{0}} p_{0} y_{0}\left(p_{0}\right)-c\left[p_{1}, p_{2}, y_{0}\left(p_{0}\right)\right]
$$

where $p_{0}$ is the monopolist's product price, $y_{0}\left(p_{0}\right)$ is the industry's demand function for the monopolist's product and $c\left[p_{1}, p_{2}, y_{0}\left(p_{0}\right)\right]$ is the cost function which describes monopolist's technology, and depends on the price of inputs that the monopolist uses in his production process, $p_{1}, p_{2}$, and the given level of production, here expressed as a function of price, $y_{0}\left(p_{0}\right)$.

By differentiating the goal function with respect to the decision variable, the first order necessary condition is obtained:

$$
y_{0}\left(p_{0}\right)+\left\{p_{0}-\frac{\partial c\left[p_{1}, p_{2}, y_{0}\left(p_{0}\right)\right]}{\partial y_{0}}\right\} \frac{\partial y_{0}\left(p_{0}\right)}{\partial p_{0}}=0
$$

where we observe a deviation of the monopolist's product price from the marginal cost, which is the mark-up and is given by the expression within the brackets. 
Let's now assume that the monopolist's technology is represented by the CobbDouglas production function,

$$
y_{0}=F\left(y_{1}, y_{2}\right)=y_{1}^{\alpha} y_{2}^{\beta}, \alpha, \beta>0,
$$

where $y_{0}$ is the monopolist's output quantity, $F\left(y_{1}, y_{2}\right)$ is the production function describing the monopolist's technology, and $y_{1}, y_{2}$ are input quantities that the monopolist employs in the production process.

Given that our chosen decision variable in the monopolist's profit maximization model is the product price, from which the product quantity can be easily obtained just by inserting the optimal product price into the demand function for the monopolist's product, the starting function representing the monopolist's technology has to be the cost function instead of the production function. From the duality theory in microeconomics, we know that the cost function represents technology as the production function equally well $[2,3,5]$.

The cost function is derived from the model of cost minimization subject to the given output level $[7,10]$ :

$$
\begin{aligned}
& \min _{y_{1}, y_{2} \geq 0} p_{1} y_{1}+p_{2} y_{2} \\
& \text { s.t. } F\left(y_{1}, y_{2}\right)=y_{1}^{\alpha} y_{2}^{\beta}=y_{0} .
\end{aligned}
$$

Base on microeconomic theory, first-order necessary conditions describe economic efficiency in which the marginal rate of technical substitution, $M R T S=\frac{\partial F / \partial y_{1}}{\partial F / \partial y_{2}}$, is equal to the input price ratio, $\frac{p_{1}}{p_{2}}$. In our case, economic efficiency is representted by the following equality,

$$
\frac{\alpha y_{2}}{\beta y_{1}}=\frac{p_{1}}{p_{2}}
$$

from which the equation of the long run expansion path in production can be derived,

$$
y_{2}=\frac{\beta p_{1}}{\alpha p_{2}} y_{1} \text {. }
$$

By inserting it in the constraint in (13), the conditional input demand functions are obtained, 


$$
y_{1}\left(p_{1}, p_{2}, y_{0}\right)=\left(\frac{\alpha}{\beta} \frac{p_{2}}{p_{1}}\right)^{\frac{\beta}{\alpha+\beta}} y_{0} \frac{1}{\alpha+\beta}
$$

and

$$
y_{2}\left(p_{1}, p_{2}, y_{0}\right)=\left(\frac{\beta}{\alpha} \frac{p_{1}}{p_{2}}\right)^{\frac{\alpha}{\alpha+\beta}} y_{0}^{\frac{1}{\alpha+\beta}}
$$

Finally, by inserting the derived input demand functions in the goal function of (13), the monopolist's cost function is obtained

$$
\begin{aligned}
& c\left(p_{1}, p_{2}, y_{0}\right)=p_{1} y_{1}\left(p_{1}, p_{2}, y_{0}\right)+p_{2} y_{2}\left(p_{1}, p_{2}, y_{0}\right) \\
& c\left(p_{1}, p_{2}, y_{0}\right)=\alpha \frac{1}{\alpha^{\frac{\alpha}{\alpha+\beta}}} \frac{1}{\beta^{\frac{\beta}{\alpha+\beta}}} p_{1}^{\frac{\alpha}{\alpha+\beta}} p_{2}^{\frac{\beta}{\alpha+\beta}} y_{0}^{\frac{1}{\alpha+\beta}}+\beta \frac{1}{\alpha^{\frac{\alpha}{\alpha+\beta}}} \frac{1}{\beta^{\frac{\beta}{\alpha+\beta}}} p_{1}^{\frac{\alpha}{\alpha+\beta}} p_{2}^{\frac{\beta}{\alpha+\beta}} y_{0}^{\frac{1}{\alpha+\beta}} \\
& c\left(p_{1}, p_{2}, y_{0}\right)=(\alpha+\beta)\left[\left(\frac{p_{1}}{\alpha}\right)^{\alpha}\left(\frac{p_{2}}{\beta}\right)^{\beta}\right]^{\frac{1}{\alpha+\beta}} y_{0}^{\frac{1}{\alpha+\beta}} .
\end{aligned}
$$

Now, let's go back to the equation (11) and express the first-order necessary condition for the monopolist's profit maximization model in our case. The expression for the marginal cost expressed as a function of the product price, $\frac{\partial c\left[p_{1}, p_{2}, y_{0}\left(p_{0}\right)\right]}{\partial y_{0}}$, is obtained by inserting $y_{0}\left(p_{0}\right)$ in

$$
\frac{\partial c\left(p_{1}, p_{2}, y_{0}\right)}{\partial y_{0}}=\left[\left(\frac{p_{1}}{\alpha}\right)^{\alpha}\left(\frac{p_{2}}{\beta}\right)^{\beta}\right]^{\frac{1}{\alpha+\beta}} y_{0}^{\frac{1-\alpha-\beta}{\alpha+\beta}}
$$

what gives us

$\frac{\partial c\left[p_{1}, p_{2}, y_{0}\left(p_{0}\right)\right]}{\partial y_{0}}=\left[\left(\frac{p_{1}}{\alpha}\right)^{\alpha}\left(\frac{p_{2}}{\beta}\right)^{\beta}\right]^{\frac{1}{\alpha+\beta}}\left(w_{0} v\right)^{\frac{1-\alpha-\beta}{(1-\nu)(\alpha+\beta)}}\left(\frac{p_{0}}{\delta}\right)^{\frac{1-\alpha-\beta}{(\rho-1)(\alpha+\beta)}}\left[\left(\frac{p_{0}{ }^{\rho}}{\delta}\right)^{\frac{1}{\rho-1}}+\left(\frac{w^{\rho}}{1-\delta}\right)^{\frac{1}{\rho-1}}\right]^{\frac{(\rho-v)(1-\alpha-\beta)}{\rho(v-1)(\alpha+\beta)}}$

Now we are in the position to discuss how the monopolist's mark-up depends on the elasticity of substitution. 


\section{Monopolist's mark-up and the elasticity of substitution}

The elasticity of substitution measures the ease of substitution between the production factors due to their price changes. It is the elasticity of the input quantities ratio with respect to the marginal rate of technical substitution,

$$
\sigma=\frac{d \ln \frac{x}{y_{0}}}{d \ln \frac{\partial G\left(y_{0}, x\right) / \partial y_{0}}{\partial G\left(y_{0}, x\right) / \partial x}} .
$$

The industry's CES production function is characterized by the constant elasticity of substitution which is shown below. The marginal rate of technical substitution is expressed as a function of the input quantities ratio,

$$
\text { MRTS }=\frac{\partial G\left(y_{0}, x\right) / \partial y_{0}}{\partial G\left(y_{0}, x\right) / \partial x}=\frac{\delta x^{\rho-1}}{(1-\delta) y_{0}^{\rho-1}}=\frac{\delta}{(1-\delta)}\left(\frac{y_{0}}{x}\right)^{1-\rho}
$$

from which it can be concluded that the elasticity of substitution is determined by the substitution parameter $\rho$,

$$
\begin{gathered}
\ln M R T S=\ln \frac{\delta}{(1-\delta)}+(\rho-1)\left(\frac{y_{0}}{x}\right) \\
d \ln M R T S=(\rho-1) \ln \left(\frac{y_{0}}{x}\right) \\
\sigma=\frac{d \ln \left(\frac{y_{0}}{x}\right)}{d \ln M R T S}=\frac{1}{1-\rho} .
\end{gathered}
$$

Below we will show how the monopolist's mark-up ratio changes when the substitutability of an industry's inputs $y_{0}$ and $x$, measured by the elasticity of substitution, changes in a few scenarios. For this purpose, let's assume that the price of an output in a perfectly competitive industry is $100, w_{0}=100$, the other industry's input price is $10, w=10$, and both prices of the monopolist's inputs are equal to $1, p_{1}=p_{2}=1$. Let the scale parameter in the industry's production function be $0.5, v=0.5$, thus assuming decreasing returns to scale. Let the distribution parameter be equal to 0.5 . To represent the monopolist's technology, 
we assume that the parameters in the monopolist's Cobb-Douglas production function, $\alpha$ and $\beta$, representing the elasticities of output with respect to each input, are each equal to 0.25 . Since the elasticity of scale is equal to the sum of these elasticities, we thus also assume that there are decreasing returns to scale in the monopolist's technology.

\subsection{Numerical illustrations}

Let the elasticity of substitution be $1.5, \sigma=1,5$. The substitution parameter is then equal to $\frac{1}{3}$. By inserting all given data in the already derived results for the monopolist's demand function in (9), we get the following expression for the monopolist's demand function

$$
\begin{aligned}
& y_{0}=\left(100 \frac{1}{2}\right)^{\frac{1}{1-1 / 2}}\left(\frac{p_{0}}{1 / 2}\right)^{\frac{1}{3}-1}\left[\left(\frac{p_{0}^{\frac{1}{3}}}{1 / 2}\right)^{\frac{1}{\frac{1}{3}-1}}+\left(\frac{10^{1 / 3}}{1-1 / 2}\right)^{\frac{1}{\frac{1}{3}-1}}\right]^{\frac{1 / 3-1 / 2}{1 / 3(1 / 2-1)}} \\
& y_{0}=50^{2}\left(2 p_{0}\right)^{-\frac{3}{2}}\left[\left(2 p_{0}^{\frac{1}{3}}\right)^{-\frac{3}{2}}+\left(2 \cdot 10^{\frac{1}{3}}\right)^{-\frac{3}{2}}\right]
\end{aligned}
$$

Combining it with the first order necessary condition for the monopolist's profit maximization problem given in (11) and with the expression for the marginal cost given in (19), which for the chosen parameters reduces to

$$
\frac{\partial c}{\partial y_{0}}=2 \cdot 50^{2}\left(2 p_{0}\right)^{-\frac{3}{2}}\left[\left(2 p_{0}^{\frac{1}{3}}\right)^{-\frac{3}{2}}+\left(2 \cdot 10^{\frac{1}{3}}\right)^{-\frac{3}{2}}\right]
$$

we get the following results: the monopolist's produced quantity is equal to 2.003, $y_{0}=2.003$, and the optimal product price is equal to $19.308, p_{0}=19.308$. The marginal cost is equal to 8.012. Therefore, the mark-up of price over marginal cost is equal to 11.296, and the mark-up ratio or the Lerner index, $L=\frac{p_{0}-M C}{p_{0}}$, is equal to $58.51 \%$. 
The main interest in this paper was to show how the monopolist's mark-up ratio changes as the elasticity of substitution changes. Different values of the elasticity of substitution and the corresponding mark-up ratios are given in the Table 1.

\begin{tabular}{|c|c|c|c|c|c|}
\hline$\sigma$ & $y_{0}$ & $p_{0}$ & $\begin{array}{c}\text { MC } \\
\text { (marginal cost) }\end{array}$ & Mark-up & Lerner index \\
\hline 1.5 & 2.003 & 19.308 & 8.012 & 11.296 & $58.51 \%$ \\
\hline 2 & 2.137 & 17.100 & 8.550 & 8.550 & $50.00 \%$ \\
\hline 3 & 2.304 & 14.692 & 9.217 & 5.475 & $37.27 \%$ \\
\hline 4 & 2.386 & 13.489 & 9.546 & 3.943 & $29.23 \%$ \\
\hline 5 & 2.430 & 12.777 & 9.722 & 3.056 & $23.91 \%$ \\
\hline 6 & 2.456 & 12.308 & 9.824 & 2.484 & $20.18 \%$ \\
\hline
\end{tabular}

Table 1: The influence of the elasticity of substitution on the monopolist's mark-up ratio

As can be seen from the table, the greater the elasticity of substitution, in other words, the greater the ease with which the industry can substitute inputs, one of which is the produced by a monopolist, the lower the monopolist's mark-up ratio. As the elasticity of substitution becomes greater, the monopolist's price is closer to the marginal cost of production. The dependence of the monopolist's product price, the marginal cost of production and mark-up on the elasticity of substitution is illustrated in Figure 1. One can also notice that $\sigma$ lies within a certain range, within which no solution was found. The minimum elasticity of substitution is affected by the industry's price $\mathrm{w}$, which does not allow the monopolist to undertake extortionate pricing. On the other hand, high substitutability of the monopolistic input with an input $x$ causes monopolist's demand to fall below its average cost causing the monopolist to go bankrupt. After that point, this model no longer exists since the monopolist has disappeared. 


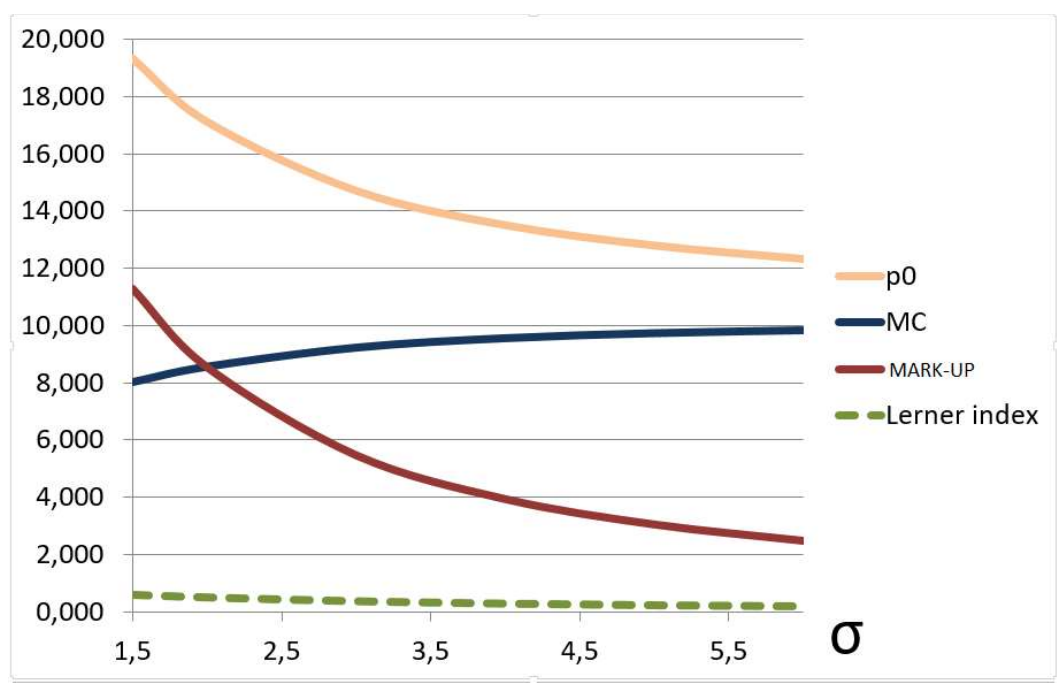

Figure 1: The monopolist's product price, the marginal cost, and the monopolist's markup as a function of the elasticity of substitution

Figure 1 clearly shows that the greater the elasticity of substitution, the lower the monopolist's mark-up and the price and marginal cost are closer to each other. Knowing that the elasticity of substitution is related to the curvature of the isoquant, in other words, the greater the elasticity of substitution, the less curved the isoquant is, allows us to illustrate below how the choice of the monopolist's product and other input by an industry changes with a change to the elasticity of substitution for a cost minimization problem. It is also obvious that the greater the elasticity of substitution, the flatter the expansion path, leaning towards a perfectly competitive input. 

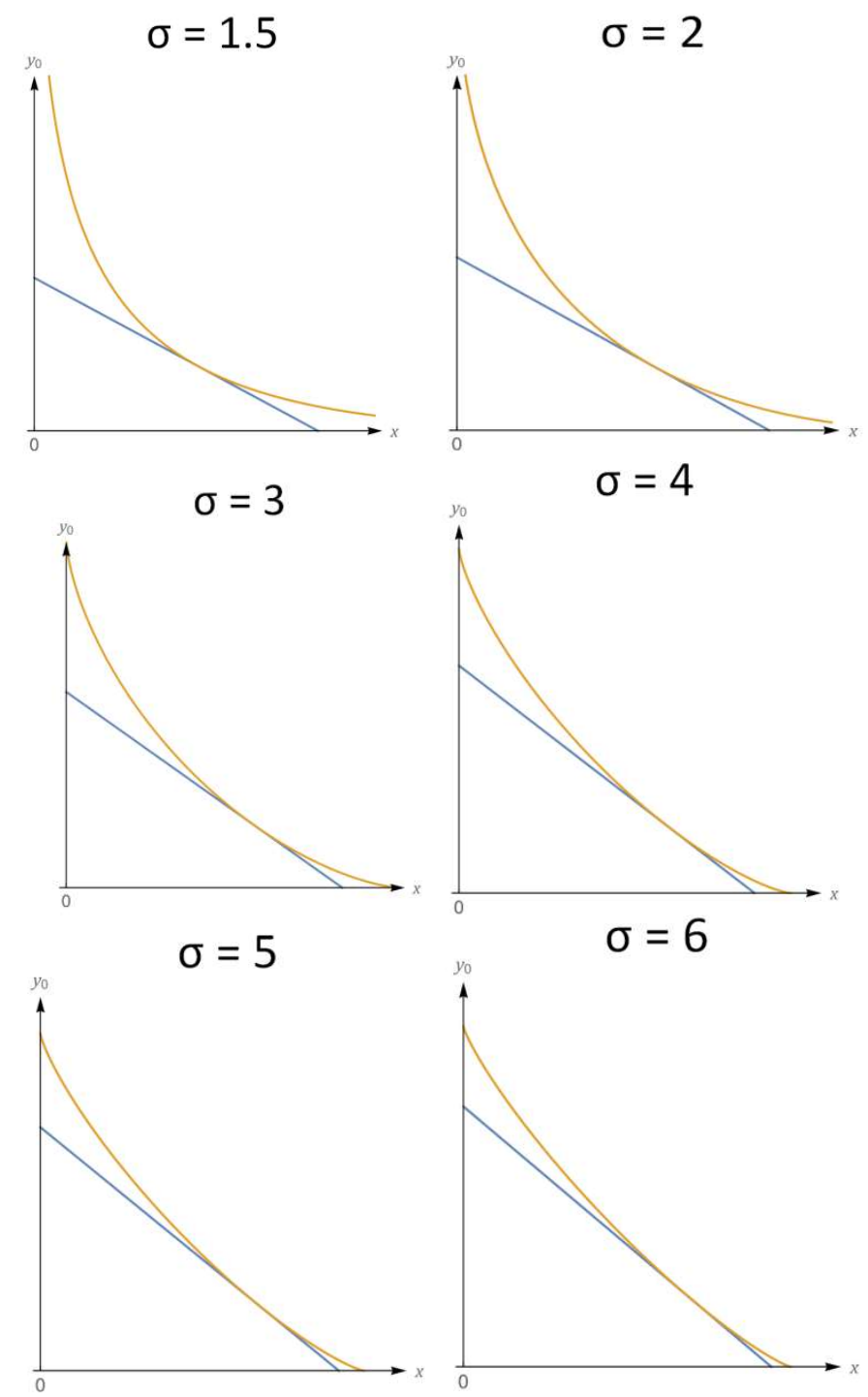

Figure 2: Industry's choice as a function of the elasticity of substitution

\section{Conclusion}

In this paper, the mark-up of product price over marginal costs for the monopolist was analyzed using Appelbaum's theoretical model. The profit maximization model of an industry which uses the monopolist's product as its input was formulated. Our goal was to express the monopolist's mark-up as a function of the industry's elasticity of substitution and to analyze how changes in the elasticity 
of substitution affect the mark-up ratio. Consequently, in representing the industry's technology, the CES production function was chosen with its substitution parameter used in the elasticity of substitution calculation.

The first task was to solve the industry's profit maximization model, where soluteon of the first-order necessary conditions yields the demand function for the monopolist's product. The next step involved using the derived demand function for the monopolist and solving the profit maximization model so as to express the mark-up of product price over marginal cost of a monopolist as a function of the elasticity of substitution. We showed for a number of numerical examples that the greater the elasticity of substitution, the lower the monopolist's mark-up ratio. This is so because the elasticity of substitution measures the ease with which the industry can substitute inputs, one of which is produced by a monopolist. As the elasticity of substitution becomes greater, the monopolist's price is closer to his marginal cost of production.

There exists a range of the elasticity of substitution beyond which the model does not provide a solution; the minimum being determined by the industry's selling price which has to justify the monopolist's high mark-up and the maximum determined by the substitutability of the monopolistic input which would render the monopolist unnecessary. In this paper, these boundaries were approximated using numerical methods, but in subsequent research, a simpler version of the model will be used in an endeavor to find functional relations and the domain of the Lerner index as a function of the elasticity of substitution between monopolistic and perfectly competitive inputs.

\section{References}

[1] Appelbaum, E. (1979). Testing price taking behavior. Journal of Econometrics, 9, 283-294.

[2] Blume, L.E. (2008). Convex Programming. In Durlauf, S. N. and Blume, L. E. (Eds.). The New Palgrave Dictionary of Economics. New York: Palgrave Macmillan. Available at: http://www.dictionaryofeconomics.com/article?id=pde2008 D000196.html [Accessed 14/04/17].

[3] Blume, L.E. (2008). Duality. In Durlauf, S. N. and Blume, L. E. (Eds.). The New Palgrave Dictionary of Economics. New York: Palgrave Macmillan. Available at: http://www.dictionaryofeconomics.com/article?id=pde2008_C000348.html [Accessed 14/04/17].

[4] Bresnahan, T. (1989). Empirical studies of industries with market power. In Schmalensee, R. and Willig, R. (Eds.). Handbook of Industrial Organization (pp. 1011-1057). Amsterdam: North Holland. 
[5] Diewert, W.E. (1982). Duality approaches to microeconomic theory. In Intriligator, M.D.; Arrow, K.J.(Eds.). Handbook of Mathematical Economics (pp. 535-599). Amsterdam: North Holland.

[6] Hall, R.E. (1986). Market structure and macroeconomic fluctuations. Brookings Papers on Economic Activity, 2, 285-338.

[7] Mas - Colell, A, Whinston, M. D, Green, J. (1995). Microeconomic Theory. New York: Oxford University Press.

[8] Roeger, W. (1995). Can imperfect competition explain the difference between primal and dual productivity measures? Journal of Political Economy, 103 (21), 316-330.

[9] Schmalensee, R. (1989). Inter-industry studies of structure and performance. In Schmalensee, R. and Willig, R. (Eds.). Handbook of Industrial Organization (pp. 951-1009). Amsterdam: North Holland.

[10] Silberberg, E. and Suen, W. (2001). The Structure of Economics: A Mathematical Analysis. Boston, Mass.: McGraw-Hill. 